\title{
Erratum to: Critical Locus of Aqueous Solutions of Sodium Chloride Revisited
}

\author{
D. A. Fuentevilla · J. V. Sengers · M. A. Anisimov
}

Published online: 9 January 2013

(C) Springer Science+Business Media New York 2013

\section{Erratum to: Int J Thermophys (2012) 33:943-958 DOI 10.1007/s10765-012-1201-5}

The following are corrections to the paper titled "Critical Locus of Aqueous Solutions of Sodium Chloride Revisited" by D.A. Fuentevilla, J.V. Sengers, and M.A. Anisimov that appeared in Int. J. Thermophys. 33, 943 (2012).

Equations 19, 20, and 21 should read:

$$
\begin{aligned}
& T_{2}(x)=T_{\mathrm{c}}^{0}\left[1+t_{1}^{\prime} x+t_{3 / 2}^{\prime} x^{3 / 2}+t_{2}^{\prime} x^{2}+t_{5 / 2}^{\prime} x^{5 / 2}+t_{3}^{\prime} x^{3}+t_{7 / 2}^{\prime} x^{7 / 2}+t_{4}^{\prime} x^{4}\right], \\
& f_{1}(x)=\frac{1}{4}[|B x-C-1|-|B x-C+1|]+\frac{1}{2}, \\
& f_{2}(x)=\frac{1}{4}[|B x-C+1|-|B x-C-1|]+\frac{1}{2} .
\end{aligned}
$$

To clarify Eq. 26,

$$
\begin{aligned}
& P_{\mathrm{c}}(x)=P_{\mathrm{c}}^{0}\left[1+p_{1} \Delta T+p_{2}(\Delta T)^{2}+p_{3}(\Delta T)^{3}+p_{4}(\Delta T)^{4}\right], \\
& \Delta T \equiv T_{\mathrm{c}}-T_{\mathrm{c}}^{0} \text { is in } \mathrm{K} .
\end{aligned}
$$

The online version of the original article can be found under doi:10.1007/s10765-012-1201-5.

D. A. Fuentevilla $\cdot$ J. V. Sengers $(\varangle) \cdot$ M. A. Anisimov

Department of Chemical and Biomolecular Engineering,

Institute for Physical Science and Technology, University of Maryland,

College Park, MD 20742, USA

e-mail: sengers@umd.edu 